\title{
Lactic Acid Fermentation of Peppers
}

\author{
Maria Rosa Alberto ${ }^{1,2}$, Maria Francisca Perera ${ }^{1}$, Mario Eduardo Arena ${ }^{1,2^{*}}$ \\ ${ }^{1}$ Facultad de Bioquímica, Química y Farmacia, Universidad Nacional de Tucumán (UNT), Tucumán, Argentina; ${ }^{2}$ Centro Científico \\ Tecnológico Tucumán - Consejo Nacional de Investigaciones Científicas y Tecnológicas (CCT-CONICET), Tucumán, Argentina. \\ Email: ${ }^{*}$ arename@fbqf.unt.edu.ar
}

Received August 21 ${ }^{\text {st }}, 2013$; revised September $21^{\text {st }}, 2013$; accepted September $30^{\text {th }}, 2013$

Copyright (C) 2013 Maria Rosa Alberto et al. This is an open access article distributed under the Creative Commons Attribution License, which permits unrestricted use, distribution, and reproduction in any medium, provided the original work is properly cited.

\begin{abstract}
Different peppers fermentations (Capsicum annum, grossum variety) were assayed: spontaneous, native microflora supplemented individually with Lactobacillus plantarum N8, Leuconostoc mesentereroides L. or Pediococcus pentosaceus $12 \mathrm{p}$ and by pure or combined cultures of these lactic acid bacteria (LAB). In order to eliminate the native flora, different kinds of heat treatment were assayed. The treatment selected was heating in autoclaved after research $3 / 4$ atmosphere and to turn off. Fermentations were carried out at $22^{\circ} \mathrm{C}$ and $30^{\circ} \mathrm{C}$ and the culture media contained $2 \%$ or $0.2 \%$ glucose and $4 \% \mathrm{NaCl}$. Sugar consumption, $\mathrm{pH}$ reduction and acid production were higher at $30^{\circ} \mathrm{C}$ than at $22^{\circ} \mathrm{C}$. At both temperatures, spontaneous fermentation showed a slower rate reduction in $\mathrm{pH}$ than inoculated samples. Diminution in $\mathrm{pH}$ in presence of $2 \%$ glucose was faster than at $0.2 \%$, but minimum $\mathrm{pH}$ was in both case lower than 3.0. Maximum growth was reached between 2 and 5 days of fermentation in all the samples assayed. After 30 days of incubation in presence of $2 \%$ glucose the survival of LAB was nearly $5 \mathrm{log}$ ufc $/ \mathrm{ml}$. The survival was higher at the lower temperature assayed for both glucose concentrations. Organoleptic properties of peppers fermented with a mixed culture of Leuconostoc mesenteroides and Pediococcus pentosaceus were found best by a human panel. This sample has a relation lactic acid/acetic acid of nearly 3 in the conditions assayed.
\end{abstract}

Keywords: Fermentation; Lactic Acid Bacteria; Peppers; Capsicum annum

\section{Introduction}

There are different forms to conserve food. One of them consists of increasing the acidity, which can be obtained artificially through addition of weak acids, or naturally by fermentation, obtaining free additive products.

Fermentation can be developed spontaneously by the native microflora or after inoculation with lactic acid bacteria (LAB). In many cases, the fermentation is led by the indigenous flora and varies regarding substrate, temperature and storage conditions; consequently, the final product has variable sensorial properties.

The use of starter cultures would be an appropriate approach for the control and optimization of the fermentation process in order to minimize variations in the organoleptic quality and microbiological stability.

LAB are responsible for the fermentation of many vegetables and this process contributes to flavour, texture and aroma characteristics of the food. Additionally it guaranties a hygienically conservation and commercial

*Corresponding author. stability.

Lactic acid fermentation requires no or very little energy in the form of heat, allows the preservation of fresh vegetables or vegetables process minimally [1] and it improves the digestibility and nutritional value of the food [2].

The demand of fermented products has experienced an important increase in recent years, as consumers recognize that fermentation plays an important and beneficial role in human nutrition, health and nourishing safety [3].

Peppers are consumed mature or immature, raw or in conserves or pickles. The information available on fermentation of peppers is little. According to data provided by the National Centre of Studies and Agricultural Investigations of Cuba (C.E.N.A.I.C.) peppers can be fermented by the native microflora. Peppers represent an important crop in the northwest of Argentina, but the product is not available all year round, and for this reason a presservation process is necessary.

Considering the technological importance of controlled fermentation of vegetables for the industry, different 
heat treatments and fermentation processes were assessed, in order to obtain an adequate product. The aim was to select a suitable starter culture in order to conduct an appropriate fermentation of Argentine peppers and to obtain a controlled process and a product of stable quality through time.

\section{Materials and Methods}

\subsection{Organisms}

Lactobacillus plantarum N8 [4], Leuconostoc mesentereroides L. [5] and Pediococcus pentosaceus 12p [6] were isolated from orange, tomato and grape, respectively. The bacteria were pre-cultured in MRS [7] broth supplemented with $15 \%(\mathrm{v} / \mathrm{v})$ tomato juice and incubated at $30^{\circ} \mathrm{C}$.

\subsection{Peppers}

Mature peppers (Capsicum annum variety grossum) were obtained from Salta province, Argentina, and carefully selected, without blows, apparent damages or microbeological alterations. The peppers were washed with abundant water and cut in fine strips. The seeds were eliminated and the peppers were processed within 48 hours of cultivation.

\subsection{Heating Procedures}

In order to eliminate the native flora without changing sensory properties, different heating techniques were assessed. Peppers were placed in $250 \mathrm{ml}$ of a sterile solution of glucose and $\mathrm{NaCl}$ with or without inoculation with LAB (Lactobacillus plantarum N8). Heating techniques assayed were: heating the samples in autoclaved with fluent steam during 5 min.; heating in autoclaved after research 3/4 atmosphere and to turn off, and heating in autoclaved during $3 \mathrm{~min}$. after research $3 / 4$ atmosphere.

Peppers (40 g) were subjected to heat treatments in a solution of $5 \%$ glucose and $4 \% \mathrm{NaCl}(250 \mathrm{ml})$. After each treatment they were incubated at $30^{\circ} \mathrm{C}$ for one week. In order to evaluate the best technique: cell counts (cfu/ $\mathrm{ml}$ ), $\mathrm{pH}$ and organoleptic characteristics such as colour of the peppers and consistency and colour of the solution were tested.

\subsection{Fermentation}

Fermentation was carried out under previously laboratory-optimized conditions, at $22^{\circ} \mathrm{C}$ and at $30^{\circ} \mathrm{C}$. The peppers $(40 \mathrm{~g})$ were incubated in $235 \mathrm{ml}$ sterile solution containing (g/l): glucose (2 and 20) and $\mathrm{NaCl}(4)$; initial pH was 5.0.

Each glucose concentration and temperature was therefore assayed with the 12 samples. Without heating:
Natural Fermentation with the native flora (NF), NF plus Lactobacillus plantarum N8; NF plus Leuconostoc mesenteroides L.; NF plus Pediococcus pentosaceus 12p. Samples with heating: without inoculation (Control); with pure cultures of Lactobacillus plantarum N8; Leuconostoc mesenteroides L. or Pediococcus pentosaceus $12 \mathrm{p}$; with mixed cultures of two pure cultures (Lactobacillus plantarum N8 and Leuconostoc mesenteroides L.; Lactobacillus plantarum N8 and Pediococcus pentosaceus $12 \mathrm{p}$ or Leuconostoc mesenteroides L. and Pediococcus pentosaceus $12 \mathrm{p}$ ); and the mixed cultures of the three strains cited.

In order to conserve the fermentation atmosphere of each sample different flasks were used for each assay $(0$, $1,2,5,10,20$ and 30 days), because once the flasks were opened the samples could not continue being incubated due to the entrance of oxygen and the risk of loss of the atmosphere generated by the fermentation process.

\subsection{Starter Culture}

For the preparation of the starter culture, microorganisms grown in MRS were centrifuged at 30,000 g during 10 min., washed with sterile distilled water, centrifuged again and resuspended in a solution of glucose and $\mathrm{NaCl}$, fitting an $\mathrm{OD}_{560}$ between 0.9 and $1\left(10^{7} \mathrm{cfu} / \mathrm{ml}\right)$. In the mixed cultures proportions were $1: 1$ and $1: 1: 1$. The bacteria were inoculated in experimental media at a total cell concentration of $1-2 \times 10^{7} \mathrm{cfu} / \mathrm{ml}$.

Samples were taken after $0,1,2,5,10,20$ and 30 days incubation for growth measurement and stored frozen $\left(-18^{\circ} \mathrm{C}\right)$ for subsequent analyses.

\subsection{Growth Measurement}

Bacterial growth was determined spectrophotometrically by measurement of optical density at $560 \mathrm{~nm}$ and by direct counting of cells on MRS agar supplemented with $15 \%(\mathrm{v} / \mathrm{v})$ tomato juice, $\mathrm{pH} 6.0$.

\subsection{Analytical Determinations}

The $\mathrm{pH}$ was determined with a $\mathrm{pH}-$ meter equipped with a glass electrode, which was calibrated against standard buffer solutions (Anedra) at $\mathrm{pH} 4.0$ and 7.0. Glucose and fructose were analysed by HPLC [8].

Organic acids were determined by HPLC analysis. Sample proteins were eliminated: $0.5 \mathrm{ml}$ of a $6 \%$ trichloroacetic acid solution was added to $0.5 \mathrm{ml}$ of the sample. The mixture was stirred on a vortex during $3 \mathrm{~min}$. and then centrifuged during $5 \mathrm{~min}$ at $30,000 \mathrm{~g}$. The pellet was discarded and the supernatant was membranefiltered $(0.45 \mu)$. The solvent used for separation was $0.01 \mathrm{~N}$ sulphuric acid. The samples were filtered using a sterile membrane of $0.45 \mu$ stirrer. HPLC was performed with Gilson equipment with an infrared detector and in- 
tegrator (Hewlett Packard, HP 3396 Series II). An ORH801 column for organic acids was used, containing a matrix of $300 \times 6.5 \mathrm{~mm}$, packed with a polymer of cationic interchange in its hydrogenated form. The column was operated at $22^{\circ} \mathrm{C}$ with a flow speed of $0.500 \mathrm{ml} / \mathrm{min}$.

\subsection{Sensorial Determinations}

Organoleptic characteristics were evaluated by a group of selected people using the double blind test. The group was integrated by 10 people of both sexes ( 6 men and 4 women) and different age ( 23 - 45 years old). The human testers evaluated the peppers fermented under the conditions assayed according to their visual aspect, flavour and aroma. The parameters were selected according to those proposed by Seseña et al. [9] for the tasting of fermented eggplants.

\subsection{Conservation of the Fermented Peppers}

The fermented peppers were conserved during three months at room temperature in the same fermentation medium or in commercial vinegar (5\% acetic acid) with $2 \% \mathrm{NaCl}$.

In the case of commercial vinegar, the peppers were washed with distilled sterile water after 30 days of fermentation and they were placed with the vinegar in sterile bottles.

\subsection{Spoilage Microorganism}

Possible spoilage of the pickles was assayed for the following microorganisms: yeasts, Clostridium botulinum and enterobacteria, using Sabouraud, SPS agar and Mac Conkey, respectively.

\subsection{Statistial Analysis}

The data were analysed by the Balanced ANOVA Test. Variable means showing statistical significance were compared using Tukey's test (Minitab Student R14).

\section{Results and Discussion}

\subsection{Heat Effect on the Organoleptic Characteristic of Peppers}

Table 1 shows the effect of heating techniques on organoleptic properties before fermentation. The results were similar for inoculated and noninoculated samples and indicate that all heat treatments affect colour and consistency of peppers.

In absence of heat (control) or in presence of fluent steam the bacteria (wild or inoculated) can grow and a decrease in $\mathrm{pH}$ was observed after 7 days of incubation. In the control media, with or without inoculation, the $\mathrm{pH}$ decreased two units, whereas the $\mathrm{pH}$ decreased only 0.3 units after seven days in samples treated with fluent steam. Consequently, fluent steam was inappropriate as a bactericidal procedure.

The lowest alteration in the sensory properties occurred when the products were put under fluent steam and when they were heating in autoclaved until research $3 / 4$ atmosphere and turn off immediately. The last procedure has the advantage that inactive the native flora and produces fewer organoleptic modifications than the same treatment during $3 \mathrm{~min}$. Therefore, the technique applied in this study to study the effect of the bacterial inoculums in the vegetable fermentation was heating peppers in solution at $3 / 4$ atmosphere in autoclave and extinguished.

\subsection{Cell Growth}

Table 2 shows maximum development of the microorganisms under the different fermentation conditions. The starters were inoculated at a concentration 100 times higher than the native flora, according to procedures proposed by Gardner et al. [10] and in agreement with Seseña et al. [9], who used lactic acid bacteria starters to carry out the fermentation of vegetables at a concentration of $10^{7} \mathrm{cfu} / \mathrm{ml}$.

Maximum values of viable cells were obtained between the second and fifth day of fermentation; as of this time the number of viable cells began diminishing or remained stable. This is common in diverse vegetable fermentation processes, such as cucumbers and cabbage for the elaboration of sauerkraut [11].

For samples without heating procedure at both glucose concentrations, in general highest growth was observed at $22^{\circ} \mathrm{C}$. This effect could be due to adaptation of the native microflora to growth at room temperature. However, inoculated samples with heat treatment showed higher growth at $30^{\circ} \mathrm{C}$ than at $22^{\circ} \mathrm{C}$. In these conditions, at glucose concentration of $2 \%$ maximum development was higher than at $0.2 \%$, nevertheless the 10 -fold higher glucose concentration did not produce a proportional increase in the cell number.

At both glucose concentrations, survival at room temperature $\left(22^{\circ} \mathrm{C}\right)$ was higher than at $30^{\circ} \mathrm{C}$, with the exception of NF samples at $2 \%$ glucose, in which survival was higher at $30^{\circ} \mathrm{C}$ (Table 3).

After 30 days incubation at $30^{\circ} \mathrm{C}$, lowest microbial survival was observed after heat treatment and inoculated with a pure culture of Leuconostoc mesenteroides or in a combination with one or two LAB at both glucose concentrations (Table 3). In the controlled fermentations and inoculated with Leuconostoc mesenteroides L. the lower survival can be explained by weak resistance to the low $\mathrm{pH}$. The results agree with those reported by Gardner et al. [10] for carrots, onions and cabbages. 
Table 1. Effect of heating techniques on sensorial properties.

\begin{tabular}{cccc}
\hline Sample treatment & Solution colour & Pepper colour & Pepper consistency $^{\mathrm{a}}$ \\
\hline Control & Transparent & Red intense & ++++ \\
Fluent steam & Yellow & Red orange & +++ \\
Autoclaved at 3/4 atmosphere and extinguished & Yellow & Red orange & +++ \\
Autoclaved at 3/4 atmosphere during 3 minutes & Orange & Orange & + \\
\hline
\end{tabular}

${ }^{\mathrm{a}}$ Consistence intensity with respect to an untreated sample $(++++)$.

Table 2. Maximum growth of microorganisms at different temperatures in presence of $0.2 \%$ and $2 \%$ glucose.

\begin{tabular}{ccccc}
\hline & \multicolumn{3}{c}{ Glucose } \\
\cline { 2 - 5 } Starter culture & \multicolumn{3}{c}{$0.2 \%$} & \multicolumn{2}{c}{$2 \%$} \\
\cline { 2 - 5 } & \multicolumn{2}{c}{$22^{\circ} \mathrm{C}$} & $30^{\circ} \mathrm{C}$ & $22^{\circ} \mathrm{C}$ \\
\hline Natural Fermentation (NF) & $8.09 \pm 0.04^{\mathrm{a}}$ & $7.57 \pm 0.04$ & $7.91 \pm 0.05$ & $6.99 \pm 0.04$ \\
$\mathrm{NF}+$ L. plantarum & $8.11 \pm 0.03$ & $7.63 \pm 0.05$ & $8.26 \pm 0.02$ & $8.19 \pm 0.04$ \\
$\mathrm{NF}+$ Lc. mesenteroides & $8.01 \pm 0.04$ & $7.67 \pm 0.06$ & $8.09 \pm 0.05$ & $8.19 \pm 0.05$ \\
$\mathrm{NF}+$ P. pentosaceus & $8.07 \pm 0.05$ & $7.92 \pm 0.04$ & $8.23 \pm 0.06$ & $8.09 \pm 0.05$ \\
L. plantarum & $7.91 \pm 0.05$ & $8.04 \pm 0.03$ & $7.96 \pm 0.05$ & $8.19 \pm 0.05$ \\
Lc. mesenteroides & $7.95 \pm 0.04$ & $8.03 \pm 0.02$ & $8.34 \pm 0.01$ & $8.35 \pm 0.02$ \\
P. pentosaceus & $7.92 \pm 0.02$ & $7.95 \pm 0.01$ & $8.09 \pm 0.05$ & $8.34 \pm 0.05$ \\
L. plantarum + P. pentosaceus & $7.50 \pm 0.05$ & $7.89 \pm 0.05$ & $8.25 \pm 0.02$ & $8.29 \pm 0.01$ \\
L. plantarum + Lc. mesenteroides & $7.80 \pm 0.02$ & $7.86 \pm 0.02$ & $8.09 \pm 0.05$ & $8.37 \pm 0.05$ \\
Lc. mesenteroides + P. pentosaceus & $7.80 \pm 0.02$ & $7.93 \pm 0.05$ & $8.29 \pm 0.03$ & $8.29 \pm 0.02$ \\
L. plantarum + Lc. mesenteroides + P. pentosaceus & $7.50 \pm 0.06$ & $7.95 \pm 0.03$ & $8.33 \pm 0.02$ & $8.35 \pm 0.01$ \\
\hline
\end{tabular}

${ }^{\mathrm{a}}$ Data are expressed in Log cfu/ml. Initial concentration $1.00 \times 10^{7}$ cells $/ \mathrm{ml}$, with the exception of Natural Fermentation in which cases the initial concentration was $3.12 \times 10^{5}$ cells $/ \mathrm{ml}$.

Table 3. Survival of microorganisms at different temperatures after 30 days of incubation in presence of $0.2 \%$ and $2 \%$ glucose at $22^{\circ} \mathrm{C}$ and $30^{\circ} \mathrm{C}$.

\begin{tabular}{|c|c|c|c|c|}
\hline \multirow{3}{*}{ Starter culture } & \multicolumn{4}{|c|}{ Glucose } \\
\hline & \multicolumn{2}{|c|}{$0.2 \%$} & \multicolumn{2}{|c|}{$2 \%$} \\
\hline & $22^{\circ} \mathrm{C}$ & $30^{\circ} \mathrm{C}$ & $22^{\circ} \mathrm{C}$ & $30^{\circ} \mathrm{C}$ \\
\hline Natural Fermentation (NF) & $5.47 \pm 0.02^{\mathrm{a}}$ & $3.38 \pm 0.03$ & $4.17 \pm 0.01$ & $5.40 \pm 0.05$ \\
\hline $\mathrm{NF}+L$. plantarum & $5.34 \pm 0.03$ & $4.00 \pm 0.05$ & $5.30 \pm 0.05$ & $5.70 \pm 0.03$ \\
\hline $\mathrm{NF}+L c$. mesenteroides & $5.17 \pm 0.02$ & $3.92 \pm 0.04$ & $5.40 \pm 0.04$ & $5.70 \pm 0.05$ \\
\hline $\mathrm{NF}+P$. pentosaceus & $4.69 \pm 0.04$ & $3.84 \pm 0.05$ & $5.20 \pm 0.02$ & $5.60 \pm 0.05$ \\
\hline L. plantarum & $4.53 \pm 0.01$ & $1.75 \pm 0.01$ & $5.60 \pm 0.04$ & $4.70 \pm 0.04$ \\
\hline Lc. mesenteroides & $4.30 \pm 0.03$ & $1.00 \pm 0.01$ & $5.40 \pm 0.02$ & $4.50 \pm 0.05$ \\
\hline P. pentosaceus & $5.30 \pm 0.05$ & $1.87 \pm 0.01$ & $5.70 \pm 0.03$ & $4.80 \pm 0.03$ \\
\hline L. plantarum $+P$. pentosaceus & $5.84 \pm 0.01$ & $3.70 \pm 0.02$ & $5.80 \pm 0.05$ & $4.80 \pm 0.05$ \\
\hline L. plantarum + Lc. mesenteroides & $5.82 \pm 0.06$ & $1.50 \pm 0.05$ & $5.45 \pm 0.02$ & $4.70 \pm 0.05$ \\
\hline Lc. mesenteroides $+P$. pentosaceus & $5.90 \pm 0.05$ & $1.30 \pm 0.02$ & $5.60 \pm 0.05$ & $4.60 \pm 0.02$ \\
\hline$L$. plantarum $+L$ c. mesenteroides $+P$. pentosaceus & $5.47 \pm 0.04$ & $1.20 \pm 0.05$ & $5.40 \pm 0.04$ & $4.70 \pm 0.01$ \\
\hline
\end{tabular}

${ }^{\mathrm{a}}$ Data are expressed in Log $\mathrm{cfu} / \mathrm{ml}$. Initial concentration $1.00 \times 10^{7}$ cells $/ \mathrm{ml}$, with the exception of Natural Fermentation in which cases the initial concentration was $3.12 \times 10^{5}$ cells $/ \mathrm{ml}$

\subsection{Analytical Determinations in Culture Media}

After 30 days of incubation production of lactic and acetic acid and consumption of glucose and fructose were determined under the different fermentation conditions (Tables 4 and 5).
Initial glucose was higher for peppers subjected to thermal treatment. This increase was due to the diffusion of the sugar from the vegetable to the solution or the liberation of glucose from sucrose (data not shown). In addition, fructose was not added to the media, but it was detected in the culture media, perhaps due to liberation 
from the peppers. The microorganisms used in the pepper fermentations consumed as much glucose as fructose.

In general, fructose and glucose consumption and acid production were higher at $30^{\circ} \mathrm{C}$ than at $22^{\circ} \mathrm{C}$. Glucose consumption was faster in the natural fermentations supplemented with pure cultures (NF + Lactobacillus plantarum; NF + Leuconostoc mesenteroides; and in NF + Pediococcus pentosaceus) than with the others fermentations including the NF (data not shown). In all natural fermentations glucose was totally consumed after 20 days of incubation.

The smallest amount of glucose was consumed by Lactobacillus plantarum as pure culture.

The mixed LAB cultures used glucose faster than pure cultures (data not shown). Not all the glucose consumed was recovered as final fermentation products; maybe, it was used for to the production of biomass and cellular maintenance. The percentage of recovery of carbon in the final products determined oscillates between 58 and 99\%. Highest recovery was found with $20 \mathrm{~g} / \mathrm{l}$ of glucose at room temperature.

Acetic acid was only formed in fermentations in the presence of Leuconostoc mesenteroides as starter culture at both glucose concentrations and in the natural fermentations in the presence of $20 \mathrm{~g} / 1$ glucose (Tables 4 and 5).
This indicates the presence of heterofermentatives microorganisms in the natural flora of the pepper. The relationship lactic acid/acetic acid in the natural fermentations did not remain constant under the different conditions; this demonstrates the variability of the natural flora of the vegetables, and therefore the inability of obtaining a product of stable quality and a reproducible process when the fermentation is spontaneous. The amount of free sugar appears to be important for the development of heterofermentatives microorganisms.

In fermentations carried out by a pure culture of Leuconostoc mesenteroides the relationship lactic acid/acetic acid was somewhat higher than 1 . In fermentations carried out by cultures of homofermentative LAB (Lactobacillus plantarum and Pediococcus pentosaceus) the production of lactic acid was high. In fermentations carried out by homo/heterofermentative mixed cultures the relationship lactic acid/acetic acid was about 3, whereas in fermentations carried out by a mixed culture of the three strains, the relationship lactic acid/acetic acid was nearly 5 .

Spyropoulou et al. [3] informed that in the fermentation of olives the production of lactic acid was 5 times higher when the initial glucose concentration increased from 1 to $10 \mathrm{~g} / 1$. Lactic acid production in our study with fermented peppers was between 8 and 10 times higher,

Table 4. Sugar consumption and organic acid production after 30 days pepper fermentations with 2 g/l of glucose.

\begin{tabular}{|c|c|c|c|c|c|c|}
\hline Temperature & Samples & $\begin{array}{c}\text { Glucose } \\
\text { consumption }\end{array}$ & $\begin{array}{c}\text { Fructose } \\
\text { consumption }\end{array}$ & $\begin{array}{l}\text { Lactic acid } \\
\text { formation }\end{array}$ & $\begin{array}{l}\text { Acetic acid } \\
\text { formation }\end{array}$ & $\begin{array}{l}\text { Lactic acid } \\
\text { acetic acid }\end{array}$ \\
\hline \multirow{10}{*}{$22^{\circ} \mathrm{C}$} & Natural Fermentation (NF) & $11.11^{\mathrm{a}}$ & 0.61 & 10.30 & 0.00 & - \\
\hline & $\mathrm{NF}+L$. plantarum & 11.11 & 0.59 & 16.81 & 0.00 & - \\
\hline & $\mathrm{NF}+L c$. mesenteroides & 11.11 & 0.66 & 14.11 & 6.66 & 2.11 \\
\hline & $\mathrm{NF}+P \cdot$ pentosaceus & 11.11 & 0.64 & 17.78 & 0.00 & - \\
\hline & L. plantarum & 12.40 & 0.94 & 18.40 & 0.00 & - \\
\hline & Lc. mesenteroides & 13.05 & 0.94 & 11.33 & 9.50 & 1.19 \\
\hline & P. pentosaceus & 13.72 & 1.05 & 20.10 & 0.00 & - \\
\hline & L. plantarum $+P$. pentosaceus & 13.57 & 1.23 & 21.78 & 0.00 & - \\
\hline & L. plantarum + Lc. mesenteroides & 13.28 & 1.20 & 15.31 & 4.37 & 3.51 \\
\hline & Lc. mesenteroides $+P$. pentosaceus & 13.22 & 1.18 & 14.00 & 4.50 & 3.11 \\
\hline \multirow{12}{*}{$30^{\circ} \mathrm{C}$} & Lc. mesenteroides $+P$. pentosaceus $+L$. plantarum & 13.33 & 0.88 & 15.55 & 3.10 & 5.02 \\
\hline & Natural Fermentation (NF) & 11.11 & 0.88 & 13.22 & 1.00 & 13.22 \\
\hline & $\mathrm{NF}+L \cdot$ plantarum & 11.11 & 0.95 & 13.55 & 0.84 & 16.13 \\
\hline & $\mathrm{NF}+$ Lc. mesenteroides & 11.11 & 0.88 & 15.40 & 7.56 & 2.04 \\
\hline & $\mathrm{NF}+P \cdot$ pentosaceus & 11.11 & 0.98 & 14.78 & 2.78 & 5.31 \\
\hline & L. plantarum & 12.78 & 1.94 & 19.20 & 0.00 & - \\
\hline & Lc. mesenteroides & 13.11 & 2.38 & 11.60 & 9.60 & 1.21 \\
\hline & P. pentosaceus & 13.89 & 2.38 & 21.10 & 0.00 & - \\
\hline & L. plantarum $+P$. pentosaceus & 13.99 & 2.29 & 22.67 & 0.00 & - \\
\hline & L. plantarum + Lc. mesenteroides & 13.77 & 2.33 & 14.78 & 4.88 & 3.02 \\
\hline & Lc. mesenteroides $+P$. pentosaceus & 13.61 & 2.38 & 15.00 & 5.30 & 2.83 \\
\hline & Lc. mesenteroides $+P$. pentosaceus $+L \cdot$ plantarum & 13.44 & 2.27 & 16.67 & 3.52 & 4.73 \\
\hline
\end{tabular}

${ }^{\mathrm{a}}$ Data are expressed in mmol/1. Initial values: glucose $11.11 \mathrm{mmol} / \mathrm{l}$ and fructose $0.88 \mathrm{mmol} / \mathrm{l}$ in media without heat treatment; glucose $14.44 \mathrm{mmol} / 1$ and fructose $2.38 \mathrm{mmol} / 1$ in media with heat treatment. Initial value of lactic and acetic acids $0.00 \mathrm{mmol} / 1$. Relative Standard deviation (RSD) $\leq 2 \%$. 
Table 5. Sugar consumption and organic acid production in pepper fermentations with 20 g/l of glucose in 30 days.

\begin{tabular}{|c|c|c|c|c|c|c|}
\hline Temperature & Samples & $\begin{array}{c}\text { Glucose } \\
\text { consumption }\end{array}$ & $\begin{array}{c}\text { Fructose } \\
\text { consumption }\end{array}$ & $\begin{array}{l}\text { Lactic acid } \\
\text { formation }\end{array}$ & $\begin{array}{l}\text { Acetic acid } \\
\text { formation }\end{array}$ & $\begin{array}{l}\text { Lactic acid/ } \\
\text { acetic acid }\end{array}$ \\
\hline \multirow{11}{*}{$22^{\circ} \mathrm{C}$} & Natural Fermentation (NF) & $111.11^{\mathrm{a}}$ & 0.55 & 68.88 & 8.30 & 8.29 \\
\hline & $\mathrm{NF}+L$. plantarum & 111.11 & 0.58 & 155.78 & 6.23 & 25.00 \\
\hline & $\mathrm{NF}+$ Lc. mesenteroides & 111.11 & 0.77 & 144.40 & 49.33 & 2.93 \\
\hline & $\mathrm{NF}+P$. pentosaceus & 111.11 & 0.60 & 147.00 & 7.32 & 20.08 \\
\hline & L. plantarum & 83.55 & 0.61 & 166.67 & 0.00 & - \\
\hline & Lc. mesenteroides & 100.00 & 1.38 & 133.33 & 98.36 & 1.35 \\
\hline & P. pentosaceus & 87.22 & 0.50 & 157.78 & 0.00 & - \\
\hline & L. plantarum $+P$. pentosaceus & 104.00 & 0.57 & 169.00 & 0.00 & - \\
\hline & L. plantarum + Lc. mesenteroides & 111.98 & 0.87 & 139.00 & 53.90 & 2.57 \\
\hline & Lc. mesenteroides $+P$. pentosaceus & 113.80 & 1.61 & 142.00 & 46.60 & 3.05 \\
\hline & Lc. mesenteroides $+P$. pentosaceus $+L$. plantarum & 94.40 & 0.50 & 143.77 & 27.33 & 5.26 \\
\hline \multirow{11}{*}{$30^{\circ} \mathrm{C}$} & Natural Fermentation (NF) & 111.11 & 1.10 & 79.68 & 5.30 & 15.03 \\
\hline & $\mathrm{NF}+$ L. plantarum & 111.11 & 1.12 & 176.67 & 4.90 & 36.06 \\
\hline & $\mathrm{NF}+$ Lc. mesenteroides & 111.11 & 0.20 & 165.40 & 56.33 & 2.94 \\
\hline & $\mathrm{NF}+P \cdot$ pentosaceus & 111.11 & 1.08 & 171.23 & 5.12 & 33.44 \\
\hline & L. plantarum & 101.10 & 1.94 & 170.62 & 0.00 & - \\
\hline & Lc. mesenteroides & 116.00 & 2.11 & 143.50 & 100.35 & 1.43 \\
\hline & P. pentosaceus & 111.80 & 1.22 & 167.78 & 0.00 & - \\
\hline & L. plantarum $+P$. pentosaceus & 112.01 & 1.15 & 178.00 & 0.00 & - \\
\hline & L. plantarum + Lc. mesenteroides & 115.15 & 1.89 & 148.99 & 56.87 & 2.61 \\
\hline & Lc. mesenteroides $+P$. pentosaceus & 114.16 & 2.11 & 152.00 & 48.60 & 3.12 \\
\hline & $L c$. mesenteroides $+P$. pentosaceus $+L \cdot$ plantarum & 116.06 & 1.88 & 145.53 & 30.33 & 4.80 \\
\hline
\end{tabular}

${ }^{\mathrm{a}}$ Data are expressed in mmol/1. Initial values: glucose $111.11 \mathrm{mmol} / 1$ and fructose $1.10 \mathrm{mmol} / \mathrm{l}$ in media without heat treatment; glucose $116.66 \mathrm{mmol} / 1$ and fructose $2.10 \mathrm{mmol} / 1 \mathrm{in}$ media with heat treatment. Initial value of lactic and acetic acids $0.00 \mathrm{mmol} / 1$. Relative Standard deviation (RSD) $\leq 2 \%$.

when the glucose concentration increased from 2 to 20 $\mathrm{g} / \mathrm{l}$. Optimum relation between lactic acid and acetic acid in the production of sauerkraut is between 3.5 and 5.0 $[10,12]$.

\section{4. pH Variations}

From an initial $\mathrm{pH}$ of 5.0, reduction in $\mathrm{pH}$ in the spontaneous fermentation was slower than in inoculated samples and the final $\mathrm{pH}$ was higher at both temperatures.

At $30^{\circ} \mathrm{C}$ in media with $2 \mathrm{~g} / 1$ glucose, after one day incubation in the inoculated samples, the $\mathrm{pH}$ deceased nearly 1.5 units, with the exception the sample inoculated with of Lactobacillus plantarum, in this case the $\mathrm{pH}$ values diminished 1.0 unit. In $\mathrm{NF}$ the $\mathrm{pH}$ diminution was 0.4 units. At $22^{\circ} \mathrm{C}$ in all the cases the diminution was lower than at $30^{\circ} \mathrm{C}$, and less than a unit.

At $30^{\circ} \mathrm{C}$, after 2 days of incubation average $\mathrm{pH}$ was 3.5. At room temperature $\left(22^{\circ} \mathrm{C}\right)$, the same value was reached after 5 days. These results could be related to a faster consumption of glucose and fructose produced in the fermentations carried out at $30^{\circ} \mathrm{C}$ than at $22^{\circ} \mathrm{C}$. Final $\mathrm{pH}$ at $22^{\circ} \mathrm{C}$ was reached between 10 and 20 days.

In the experiment with $20 \mathrm{~g} / \mathrm{l}$ of glucose, microbial growth was higher and the decrease in $\mathrm{pH}$ was faster than that in media supplemented with $2 \mathrm{~g} / \mathrm{l}$ of glucose. Acid production in pepper fermentation depended on the initial glucose concentration.

Consequently, fermentation carried out at $30^{\circ} \mathrm{C}$ and with $20 \mathrm{~g} / \mathrm{l}$ of glucose and using starter cultures confers more microbiological stability to the product, because the rapid decrease in $\mathrm{pH}$ compared to fermentations at $22^{\circ} \mathrm{C}$ or at $0.2 \mathrm{~g} / 1$ or by spontaneous fermentations.

Nevertheless, fermentation of peppers with a lower glucose concentration allowed a reduction in the sugar used and therefore lowers cost and could reduce the development of NF heterofermentatives (no formation of acetic acid).

\subsection{Organoleptic Evaluation}

Organoleptic evaluation of the peppers fermented under the different conditions, revealed that those fermented by a mixed culture of Leuconostoc mesenteroides and Pediococcus pentosaceus at both temperatures were considered the best. At least $70 \%$ of the members of the tasting panel agreed and no significant difference was observed between either temperatures. However, the tasting panel found the peppers fermented at lower temperature slightly sweeter, which is probably due to the elevated concentration of residual sugars in the fermentation at $22^{\circ} \mathrm{C}$ (Table 6). 
Table 6. Organoleptic evaluation of the fermented peppers.

\begin{tabular}{|c|c|c|c|c|c|c|c|c|c|c|c|c|}
\hline \multicolumn{2}{|c|}{ OLFACTORY EXAMINATION } & 1 & 2 & 3 & 4 & 5 & 6 & 7 & 8 & 9 & 10 & 11 \\
\hline \multicolumn{13}{|c|}{ Exaggerated } \\
\hline \multirow{4}{*}{ Scent intensity } & Powerful & & & & & & $\mathrm{X}$ & & & & $\mathrm{X}$ & \\
\hline & Sufficient & $\mathrm{X}$ & $\mathrm{X}$ & $\mathrm{X}$ & $\mathrm{X}$ & $\mathrm{X}$ & & $\mathrm{X}$ & $\mathrm{X}$ & $\mathrm{X}$ & & $\mathrm{X}$ \\
\hline & Weak & & & & & & & & & & & \\
\hline & Nonexistent & & & & & & & & & & & \\
\hline \multicolumn{13}{|c|}{ VISUAL EXAMINATION } \\
\hline \multirow{4}{*}{ Colour intensity } & + & & & & & & & & & & & \\
\hline & ++ & & & & & $\mathrm{X}$ & & & $\mathrm{X}$ & & & \\
\hline & +++ & $\mathrm{X}$ & $\mathrm{X}$ & $\mathrm{X}$ & $\mathrm{X}$ & & $\mathrm{X}$ & $\mathrm{X}$ & & $\mathrm{X}$ & & $\mathrm{X}$ \\
\hline & ++++ & & & & & & & & & & $\mathrm{X}$ & \\
\hline \multicolumn{13}{|c|}{ FLAVOUR EXAMINATION } \\
\hline \multirow{4}{*}{ Acidity } & Excessive & & & & & & $\mathrm{X}$ & $\mathrm{X}$ & $\mathrm{X}$ & $\mathrm{X}$ & & $\mathrm{X}$ \\
\hline & Balanced & & & & $\mathrm{X}$ & $\mathrm{X}$ & & & & & $\mathrm{X}$ & \\
\hline & Insufficient & $\mathrm{X}$ & $\mathrm{X}$ & $\mathrm{X}$ & & & & & & & & \\
\hline & Smooth & & & $\mathrm{X}$ & & & $\mathrm{X}$ & $\mathrm{X}$ & $\mathrm{X}$ & $\mathrm{X}$ & $\mathrm{X}$ & \\
\hline \multirow[t]{3}{*}{ Texture } & Moderate & $\mathrm{X}$ & $\mathrm{X}$ & & $\mathrm{X}$ & $\mathrm{X}$ & & & & & & $\mathrm{X}$ \\
\hline & Rough & & & & & & & & & & & \\
\hline & Soft & $\mathrm{X}$ & $\mathrm{X}$ & $\mathrm{X}$ & $\mathrm{X}$ & & & & & & & \\
\hline \multirow[t]{3}{*}{ Consistency } & Interval & & & & & $\mathrm{X}$ & & & & $\mathrm{X}$ & $\mathrm{X}$ & \\
\hline & Hard & & & & & & $\mathrm{X}$ & $\mathrm{X}$ & $\mathrm{X}$ & & & $\mathrm{X}$ \\
\hline & & & AL I & MIN & $\mathrm{OON}$ & & & & & & & \\
\hline \multicolumn{2}{|c|}{ Highest conformity } & & & & & & & & & & $\mathrm{X}$ & \\
\hline
\end{tabular}

1: Natural Fermentation (NF); 2: NF + L. plantarum +; 3: NF + Lc. mesenteroides; 4: NF + P. pentosaceus; 5: L. plantarum; 6: Lc. mesenteroides; 7: P. pentosaceus; 8: L. plantarum + P. pentosaceus; 9: L. plantarum + Lc. mesenteroides; 10: Lc. mesenteroides + P. pentosaceus; and 11: L. plantarum + Lc. mesenteroides $+P$. pentosaceus.

The fact that a combination of one heterofermentative, Leuconostoc mesenteroides L., and one homofermentative, Pediococcus pentosaceus $12 \mathrm{p}$, was found the best and selected as a starter by the panel members, is in agreement with results reported previously for other vegetables.

The relation lactic acid/acetic acid for the starter of pepper fermentation, selected by the tasting panel (Leuconostoc mesenteroides L.-Pediococcus pentosaceus $12 \mathrm{p}$ ), was between 2.8 and 3.1 . In the mixed culture, the acetic acid production by heterofermentative microorganisms contributed to reach a balanced acidity in the taste examination.

Gardner et al. [10] used pure and mixed starters of three lactic acid bacteria: Lactobacillus plantarum NK 312, Pediococcus acidilactici AFERM 772 and Leuconostoc mesenteroides BLAC, to lead the fermentation of juice from vegetable mixtures (onion, carrot, beet and cabbage) and selected as most suitable starter to lead the process to the constituted by the three lactic acid bacteria.

\subsection{Conservation of Fermented Peppers}

Before each organoleptic evaluation samples were tested in order to determine the presence of spoilage microorganisms. Clostridum or enterobacteria could not be detected in the fermentation media, probably because of the low $\mathrm{pH}$ obtained after a short period of time and the production of $\mathrm{CO}_{2}$ that can eliminate $\mathrm{O}_{2}$ from the fermentation atmosphere. A superficial layer with a creamy white colour could be observed at $22^{\circ} \mathrm{C}$ in the natural fermentation after 5 days and in the nonheating and inoculated fermentations after 10 days. The layer was examined optically and identified microscopically as yeasts. At $30^{\circ} \mathrm{C}$ in the nonheating and inoculated fermentations presence of yeasts was not detected by plating out on Sabouraud medium. LAB under adequate growth conditions seem to inhibit the development of yeasts.

Our results agree with those observed previously by Gardner et al. [10], who informed that when inoculating vegetable juices with a mixture of three LAB (Lactobacillus plantarum NK 312, Pediococcus acidilactici AFERM 772 and Leuconostoc mesenteroides BLAC) to carry out the fermentation, the yeasts growth was inhibited.

According to Bayrock and Ingledew [13], inhibition of yeasts can be due to their competition for nutrients with lactic acid bacteria and not to the production of lactic acid. 
Bonestroo et al. [14] outlined that the inhibition of spoilage yeasts in fermented salads is probably due to a combination of the formation of lactic acid and $\mathrm{CO}_{2}$ and the reduction in concentration of residual oxygen.

The large presence of health-promoting compounds and the sensory features of pepper fruits may encourage food processing that aims at preserving functional compounds and agreeable sensory characteristics for extended shelf-life, possibly at room temperature [15-18].

Di Cagno et al. [17] demonstrated that fermentation by autochthonous and selected lactic acid bacteria strains (Lactobacillus plantarum, Lactobacillus curvatus and Weissella confusa), combined with heat treatment, allowed the manufacture and storage at room temperature (30 days) of safe red and yellow peppers with sensory attributes similar to raw fruits. The microbial and sensory features of peppers stored with sunflower seeds oil were almost similar to those stored without suspending liquid.

In this study, two possible methods for pepper conservation were assayed after 30 days of fermentation: one in the some fermentation media and the other remove the peppers to the fermentation media and conserve them in commercial vinegar.

The peppers conserved in the same media of fermentation during 3 months, did not present significant modifycations in the sensorial property. The survival of LAB after 3 months stayed in the order to $10^{4} \mathrm{cfu} / \mathrm{ml}$, suggesting the possibility of use pepper fermentation as source of probiotic. This could be given additional value to the fermentation of vegetables, and consider it as a functional food.

Peppers conserved by the same period of time in vinegar, were excessively acid and had bleached completely after two months of storage, probably due to destabilization of the peppers caused by the acidity. LAB, after 3 months, were not detected.

Growth of pathogenic microorganisms was not detected under either conservation condition. However, it is more convenient to conserve fermented vegetables in their own fermentation media, because they do not negatively modify the sensorial properties and the survival of LAB after 3 months of storage are high.

Peppers in commercial conserves lack skin, whereas in this peppers fermentation, the peppers were not peeled, since the fermentation process improves the digestibility of the skin.

From the results it is possible to suggest that fermentations be controlled at $30^{\circ} \mathrm{C}$, because the fast drop in $\mathrm{pH}$ gives greater microbiological stability to the product.

Fermented vegetables are generally not pasteurized and do not have artificial preservatives. The use of LAB cultures with adequate technological conditions could acidify the media quickly and thus diminishing the possibility of their deterioration during storage. LAB com- pete with other microorganisms for nutrients and space, so their growth eliminates undesirable microorganisms. Biopreservation is mainly due to the synthesis of a wide variety of antagonistic primary and secondary metabolites including organic acids, carbon dioxide [19]. Lactic acid fermentation undoubtedly represents the easiest and the most suitable way for increasing the daily consumption of fresh-like vegetables and fruits [18]. Moreover BAL consumption can exert beneficial effects on health level.

In this work we have demonstrated the possibility of obtaining fermented peppers with excellent organoleptic qualities without inclusion of artificial additives. Controlled lactic acid fermentation of Capsicum annum could be an interesting technological procedure to conserve this product.

\section{Acknowledgements}

This work was supported by grants from Consejo Nacional de Investigaciones Científicas y Técnicas (CONICET), Consejo de Investigaciones de la Universi-dad Nacional de Tucumán (CIUNT).

\section{REFERENCES}

[1] K. H. Steinkraus, "Lactic Acid Fermentation in Production of Foods from Vegetables, Cereals and Legumes," Antonie Van Leewenhoek, Vol. 49, No. 3, 1983, pp. 337 348. http://dx.doi.org/10.1007/BF00399508

[2] E. Caplice and G. F. Fittzgerald, "Food Fermentations: Role of Microorganisms in Food Production and Preservation," International Journal of Food Microbiology, Vol. 50, No. 1-2, 1999, pp.131-149.

http://dx.doi.org/10.1016/S0168-1605(99)00082-3

[3] K. E. Spyropoulou, N. G. Chorianopoulos, P. N. Skandamis and G. J. Nychas, "Survival de Escherichia coli O157: H7 during the Fermentation of Spanish Style Green Olives (Conserveola Variety) Supplemented with Different Carbon Sources," International Journal of Food Microbiology, Vol. 66, 2001, pp. 3-11.

http://dx.doi.org/10.1016/S0168-1605(00)00510-9.

[4] M. E. Arena, F. M. Saguir and M. C. Manca de Nadra, "Inhibition of Growth of Lactobacillus plantarum Isolated from Citrus Fruits in the Presence of Organics Acids," Microbiology-Aliments-Nutrition, Vol. 14, No. 3, 1996, pp. 219-226.

[5] S. A. Sajur, F. M. Saguir and M. C. Manca de Nadra, "Effect of Dominant Specie of Lactic Acid Bacteria from Tomato on Natural Microflora Development in Tomato Purée," Food Control, Vol. 18, No. 5, 2007, pp. 594-600. http://dx.doi.org/10.1016/j.foodcont.2006.02.006

[6] A. M. Strasser de Saad and M. C. Manca de Nadra, "Isolation and Identification of Lactic Acid Bacteria from Cafayate (Argentina) Wines," Microbiology-Aliments -Nutrition, Vol. 5, 1987, pp. 45-49.

[7] J. C. De Man, M. Rogosa and M. R. Sharpe, "A Medium 
for the Cultivation of Lactobacilli," Journal of Applied Bacteriology, Vol. 23, No. 1, 1960, pp. 130-135. http://dx.doi.org/10.1111/j.1365-2672.1960.tb00188.x

[8] A. M. Wilson, T. M. Work, A. A. Bushway and R. J. Bushway, "HPLC Determination of Fructose, Glucose, and Sucrose in Potatoes," Journal of Food Science, Vol. 46, No. 1, 1981, pp. 300-301. http://dx.doi.org/10.1111/j.1365-2621.1981.tb14589.x

[9] S. Seseña, I. Sanchez Hurtado, M. A. González Vinas and L. Palop, "Contribution of Starter Culture to the Sensory Characteristics of Fermented Almagro Eggplants," International Journal of Food Microbiology, Vol. 67, No. 3, 2001, pp. 197-205. http://dx.doi.org/10.1016/S0168-1605(01)00442-1

[10] N. J. Gardner, T. Savard, P. Obermeier, G. Caldwell and C. P. Champagne, "Selection and Characterization of Mixed Starter Cultures for Lactic Acid Fermentation of Carrot, Cabbage, Beet and Onion Vegetable Mixtures," International Journal of Food Microbiology, Vol. 64, No. 3, 2001, pp. 261-275. http://dx.doi.org/10.1016/S0168-1605(00)00461-X

[11] W. C. Frazir and D. C. Westhoff, "Contaminación, Conservación y Alteración de las Hortalizas y de las Frutas," Food Microbiology, McGraw Hill, New York, 1993, pp. 259-288.

[12] M. R. Adams and M. O. Mosa, "Alimentos Fermentados y Alimentos Microbianos," Microbiología de los Alimentos, Zaragoza, 1995.

[13] D. P. Bayrock and W. M. Ingledew, "Inhibition of Yeast by Lactic Acid Bacteria in Continuous Culture: Nutrient Depletion and/or Acid Toxicity?" Journal of Industrial Microbiology and Biotechnology, Vol. 31, No. 8, 2004, pp. 362-368.

http://dx.doi.org/10.1007/s10295-004-0156-3
[14] M. H. Bonestroo, J. C. Wit, B. J. Kusters and F. M. Rombouts, "Inhibition of the Growth of Yeasts in Fermented Salads," International Journal of Food Microbiology, Vol. 17, No. 4, 1993, pp. 311-320. http://dx.doi.org/10.1016/0168-1605(93)90201-Q

[15] J. M. Navarro, P. Flores, C. Garrido and V. Martinez, "Changes in the Contents of Antioxidants Compounds in Pepper Fruits at Different Ripening Stages, as Affected by Salinity," Food Chemistry, Vol. 96, No. 1, 2006, pp. 66-73. http://dx.doi.org/10.1016/j.foodchem.2005.01.057

[16] S. M. Castro, J. A. Saraiva, J. A. Lopes-da-Silva, I. Delgadillo, A. Van Loey, C. Smout and M. Hendrickx, "Effect of Thermal Blanching and High Pressure Treatments on Sweet Green and Red Bell Peppers Fruits (Capsicum annum L.)," Food Chemistry, Vol. 107, No. 4, 2008, pp. 1436-1449.

http://dx.doi.org/10.1016/j.foodchem.2007.09.074

[17] R. Di Cagno, R. F. Surico, G. Minervini and M. De Angelis, "Use of Autochthonous Starters to Ferment Red and Yellow Peppers (Capsicum annum L.) to Be Stored at Room Temperature," International Journal of Food Microbiology, Vol. 130, No. 2, 2009, pp. 108-116. http://dx.doi.org/10.1016/j.ijfoodmicro.2009.01.019

[18] R. Di Cagno, R. Coda, M. De Angelis and M. Gobbetti, "Exploitation of Vegetables and Fruits through Lactic Acid Fermentation," Food Microbiology, Vol. 33, No. 1, 2013, pp. 1-10. http://dx.doi.org/10.1016/j.fm.2012.09.003

[19] L. Fan and L. Truelstrup Hansen, "Fermentation and Biopreservation of Plant Based Foods with Lactic Acid Bacteria," In: Y. H. Hui, Ed., Handbook of Plant Based Fermented Food and Beverage Technology, 2nd Edition, CRC Press, Boca Raton, pp. 35-48. 